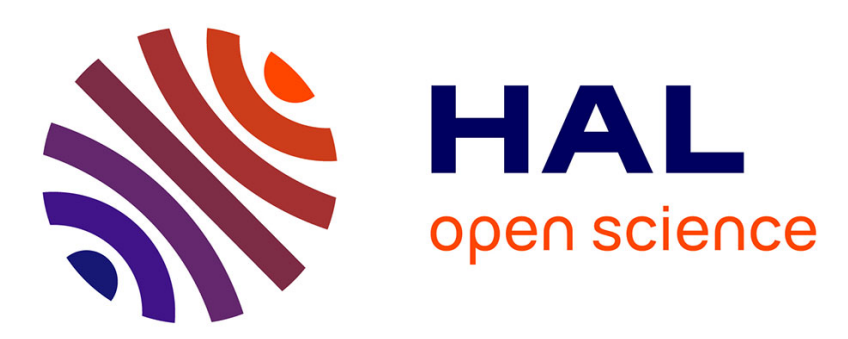

\title{
INVESTIGATION OF POLYMER MESOPHASES BY OPTICAL MICROSCOPY
}

\author{
B. Fayolle, C. Noel, J. Billard
}

\section{To cite this version:}

B. Fayolle, C. Noel, J. Billard. INVESTIGATION OF POLYMER MESOPHASES BY OPTICAL MICROSCOPY. Journal de Physique Colloques, 1979, 40 (C3), pp.C3-485-C3-489. 10.1051/jphyscol:1979397 . jpa-00218794

\section{HAL Id: jpa-00218794 https://hal.science/jpa-00218794}

Submitted on 1 Jan 1979

HAL is a multi-disciplinary open access archive for the deposit and dissemination of scientific research documents, whether they are published or not. The documents may come from teaching and research institutions in France or abroad, or from public or private research centers.
L'archive ouverte pluridisciplinaire HAL, est destinée au dépôt et à la diffusion de documents scientifiques de niveau recherche, publiés ou non, émanant des établissements d'enseignement et de recherche français ou étrangers, des laboratoires publics ou privés. 


\title{
INVESTIGATION OF POLYMER MESOPHASES BY OPTICAL MICROSCOPY
}

\author{
B. FAYOLLE $\left({ }^{*}\right)$, C. NOEL $\left({ }^{* *}\right)$ and J. BILLARD $\left({ }^{* * *}\right)$
}

(*) Rhône-Poulenc, Centre de Recherches des Carrières, 69190 Saint Fons, France

(**) Laboratoire PCSM, 10, rue Vauquelin, 75231 Paris Cedex 05, France

(***) Laboratoire de Physique de la Matière Condensée, Collège de France, 75231 Paris Cedex 05, France

\begin{abstract}
Résumé. - Au moyen de l'analyse thermique différentielle et de la microscopie optique un co[poly(éthylène téréphtalate)-p-oxybenzoate] contenant $80 \%$ d'unités oxybenzoate et un copolyester derivé du terphényle ont été étudiés. Les diagrammes de phase, établis par la méthode de contact avec des substances de référence, montrent que les mésophases de ces polymères sont respectivement nématique et smectique $C$. Ces mésophases donnent, par addition de substances optiquement actives, des phases cholestériques et smectiques $\mathbf{C}$ torsadées.
\end{abstract}

\begin{abstract}
A co[poly(ethylene terephthalate)-p-oxybenzoate] containing 80 mole $\%$ oxybenzoate units and a copolyester belonging to series of terphenyl derivatives are investigated by DSC and optical microscopy. Their mesophases are identified, by isomorphism with known phases, as nematic and smectic mesophases, respectively. Chiral compounds on addition to these mesophases, cause the formation of the typical textures of cholesterics and twisted smectics $C$.
\end{abstract}

1. Introduction. - Most of the known experimental work concerning polymers exhibiting mesophasic behavior deals with polymers having the mesophase originating molecule part inserted in the side chain [1]. However, an ever increasing number of highly aromatic polyazomethines and polyesters with the mesogenic group in the main chain has been synthesized [2-6]. They give anisotropic phases by melting and unusually anisotropic molded articles. Optical microscopic observations $[2,8]$, the dependence of the melt viscosity on molecular structure, composition and shear rate [3,7] wide-line NMR data [7] and X-Rays measurements [9] provide strong evidence that these polymers show a transformation from a crystalline to a mesomorphic state. However, these experimental results are not sufficient to warrant identification of the mesophases observed as nematic or smectic mesophases.

Recently we have determined the nature of the mesophase of a copolyazomethine (A) :

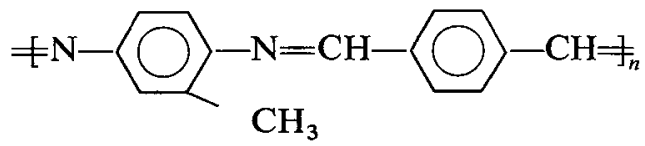

by establishing its isomorphy with nematic mesophases of reference compounds [10]. In this work, the same method is used for investigations of two copolyesters. The shape of the isobaric phase diagrams is determined using the well-known contact method [11]. Results from differential scanning calorimetry (DSC) and thermal polarizing microscopy are also given.

2. Experimental part. - The copolyazomethine [A] was synthesized as described in the reference [6]. It has an inherent viscosity at $25^{\circ} \mathrm{C}$ of $0.37 \mathrm{dl} / \mathrm{g}$ at a concentration of $0.5 \mathrm{~g} / \mathrm{dl}$ in methanesulfonic acid.

The copolyester B of p-oxybenzoyl (I) and ethylene terephthalate (II) containing $20 \mathrm{~mole} \%$ of the moiety II was obtained from the Tennessee Eastman Company<smiles>COc1ccc(C(=O)COCCOC(=O)c2ccc(C(C)=O)cc2)cc1</smiles>

The copolyester $\mathrm{C}$ was prepared in the Centre de Recherches des Carrières de Rhône-Poulenc, Saint-Fons, France, by standard methods via the following scheme :

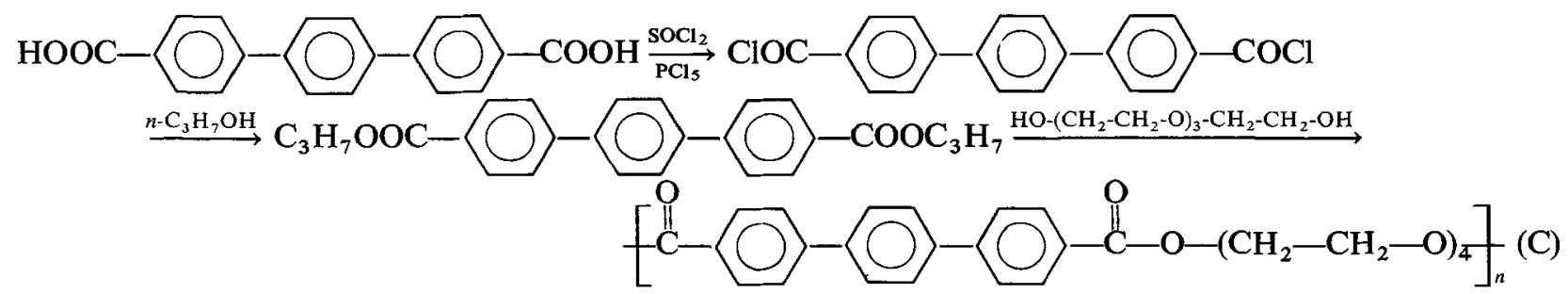


It has an inherent viscosity at $25^{\circ} \mathrm{C}$ of $0.6 \mathrm{dl} / \mathrm{g}$ at a concentration of $0.5 \mathrm{~g} / \mathrm{dl}$ in dichloracetic acid.

The reference compounds used to identify the polymeric mesophases are the $\mathrm{N}, \mathrm{N}^{\prime}$-di(p-methoxybenzylidene) $\alpha, \alpha^{\prime}$-bi-p-toluidine (E) (Eastman Organic Chemicals) for the copolyester B and the terephthal-bis(p-butyl-aniline) (F) (12) for the copolyester C

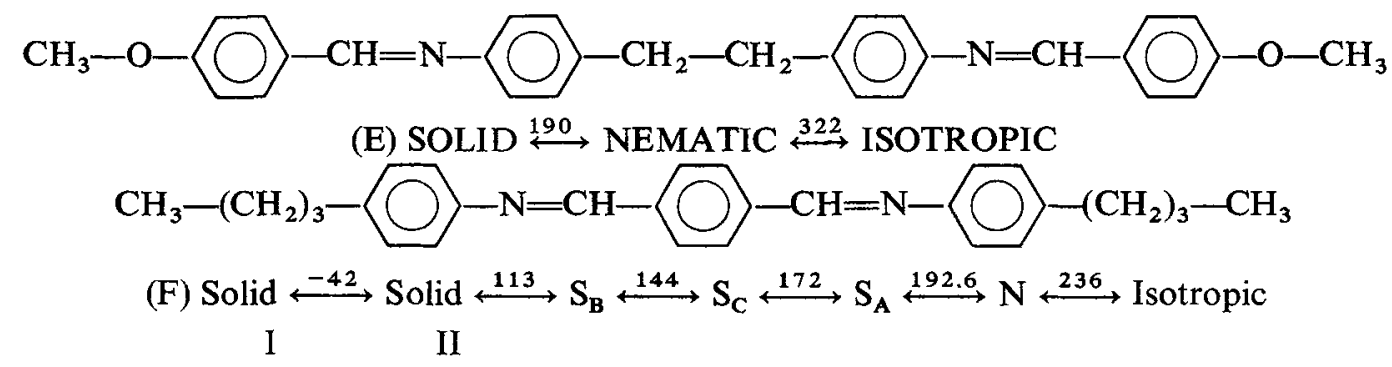

The conversion of polymeric mesophases to the cholesteric or the twisted smectic $\mathrm{C}$ form is performed by the addition of the following optically active solutes : the 4'-(2-methyl hexyloxy) biphenyl-4-carboxylic acid (G) [13],

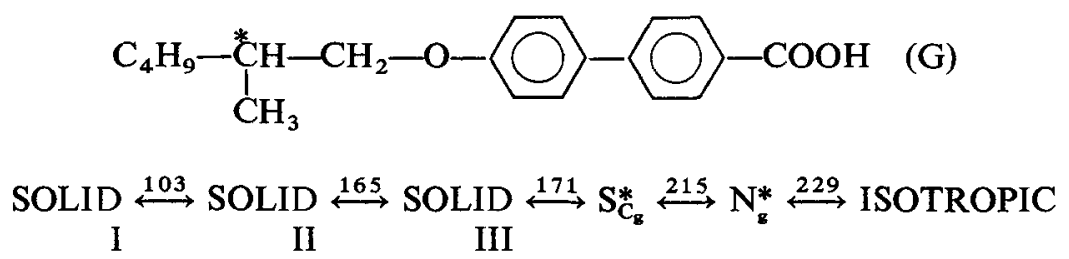

and the terephthalylidene-bis-4- $((+)-4$ '-methylhexyloxy)-aniline (14) (H)

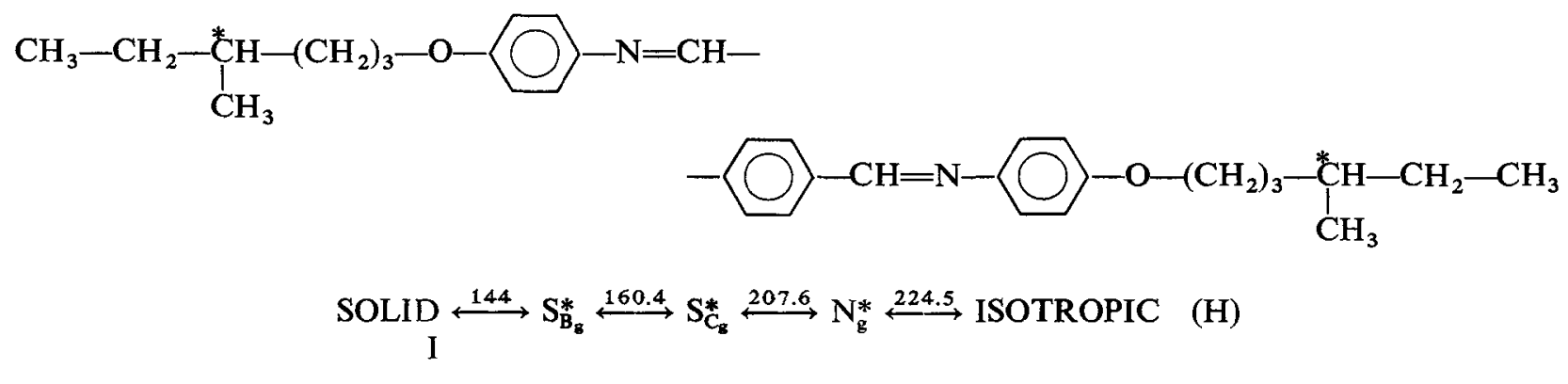

Phase transition temperatures and enthalpies are measured using a differential thermal analyzer (Du Pont 990). The samples are examined under dry nitrogen flow. Scanning rates of $10 \mathrm{~K} / \mathrm{min}$ are used. The transition temperatures are taken as the endotherm maximum point. For the evaluation of the transition enthalpies an indium sample is used as reference standard.

The textures of the phases are observed between cover slips with a polarizing microscope (Leitz, Panphot) equipped with a heating stage [Mettler FP5 or Leitz 1377].

3. Results. - The transition enthalpies and temperatures are given in the table I.

$3.1 \mathrm{CO}$ [POLY(ETHYLENE TEREPHTHALATE)-p-OXYBENZOATE]. - DSC scans show a first order transition at $298^{\circ} \mathrm{C}$. No upper transition is observed up to $350^{\circ} \mathrm{C}$. Observations with the polarizing microscope indicate the formation of a birefringent melt at the same temperature. As shown in figure 1, the copo- lyester mesophase has a typical threaded Schlieren texture. It is isomorphic with the nematic phase of the reference compound $\mathrm{E}$. The isobaric phase diagram of mixtures of the copolyester $B$ and the substance $\mathrm{E}$ shows a nematic eutectic point at $160^{\circ} \mathrm{C}$. The equilibrium spindle between the nematic and liquid phases is regular.

The copolyester mesophase is also isomorphic with the nematic phase of the copolyazomethine A which is itself isomorphic with the nematic phases of known reference compounds [10]. The isobaric phase

TABLE I

Transition temperatures $\left({ }^{\circ} \mathrm{C}\right)$ and enthalpies (kcal/monomer unit)

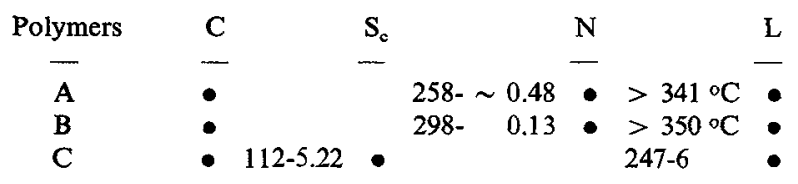




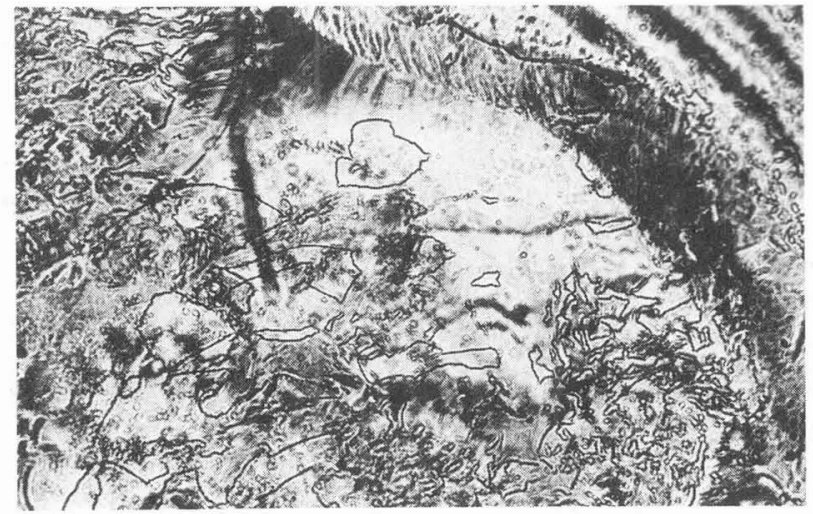

FIG. 1. - Typical threaded Schlieren texture of the nematic phase.

diagram of mixtures of the copolyester $\mathrm{B}$ and the copolyazomethine A shows an eutectic at $239^{\circ} \mathrm{C}$.

It is worthwhile to note that the nematic phases of $\mathbf{B}$ and $\mathbf{A}$ can be transformed to cholesteric ones by dissolving an optically active compound in them. The figure 2 shows that the copolyazomethine $\mathrm{A}$ is totally miscible with the optically active compound $\mathrm{H}$ in the nematic-cholesteric state. This chiral compound, on addition to the copolyazomethine mesophase, causes the formation of the typical planar texture of cholesterics. In the range of small content of the chiral compound parallel lines are formed as shown in figure $3 a$. As the content of $\mathrm{H}$ increases moiré fringes appear (Fig. 3b). The planar texture exhibits typical colours of rotatory power's dispersion.

Similar results are observed with the copolyester B. The isobaric phase diagram of this copolyester and the chiral compound $\mathrm{G}$ shows an eutectic at $149^{\circ} \mathrm{C}$. The cholesteric mesophase appears at $209^{\circ} \mathrm{C}$. The

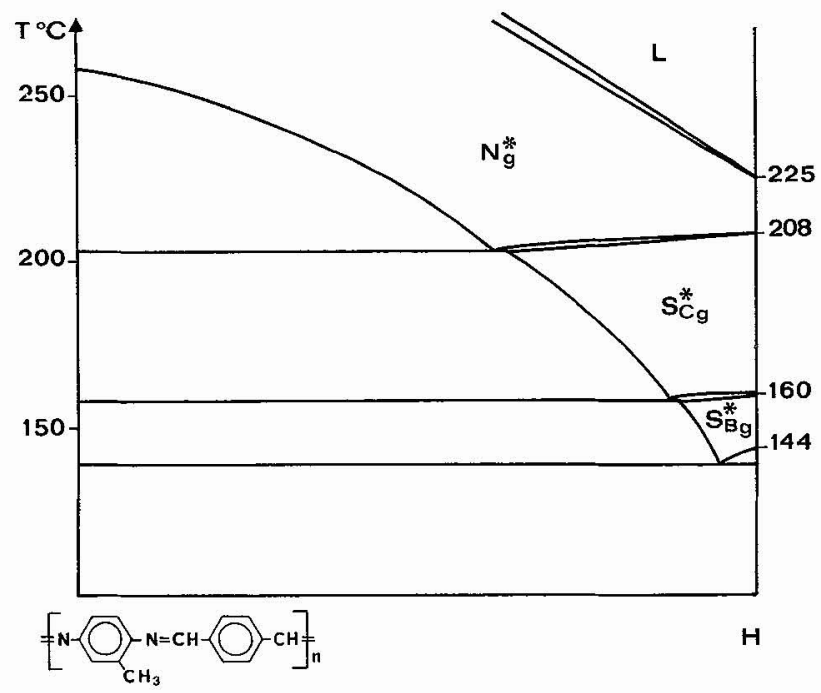

FIG. 2. - Isobaric phase diagram of the copolyazomethine $A$ and the chiral compound $\mathrm{H}$.

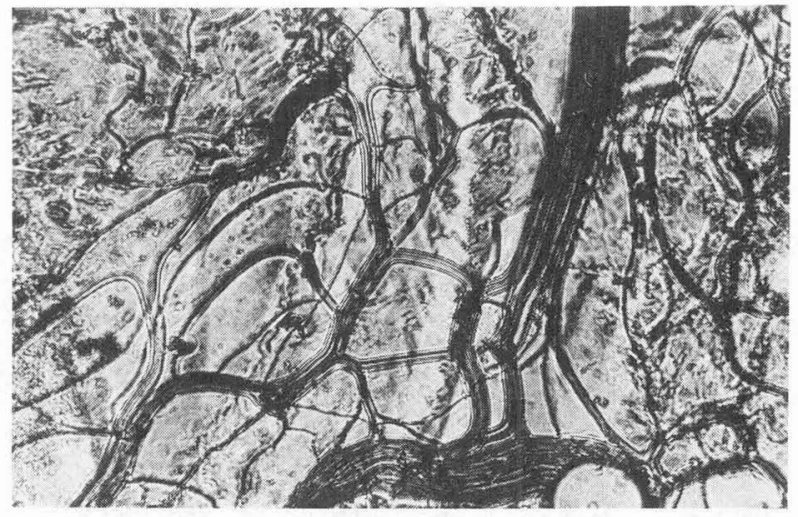

a)

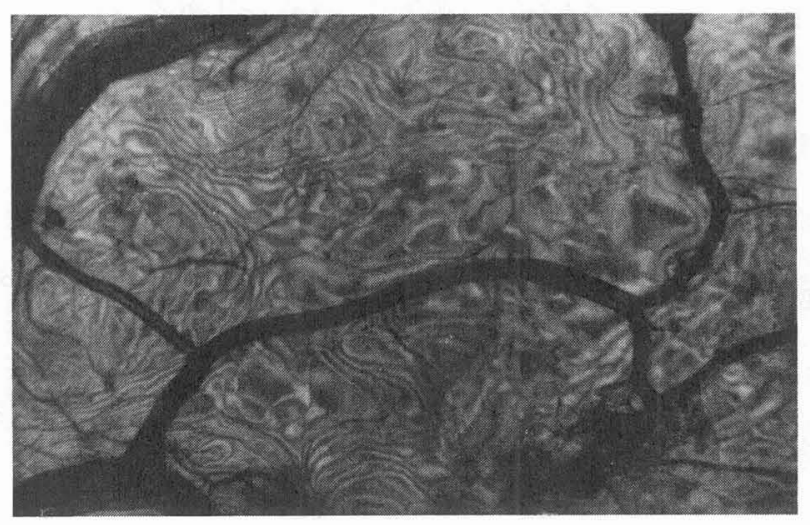

b)

FIG. 3. - Typical plane texture obtained at $260^{\circ} \mathrm{C}$ by the addition of the optically active compound $\mathbf{H}$ to the copolyazomethine $\mathrm{A}$; (a) parallel lines, $(b)$ moiré fringes.

equilibrium spindle between the cholesteric and liquid phases shows a minimum at $223^{\circ} \mathrm{C}$.

3.2 Copolyester C. - DSC scans show that two first order transitions separated by $135^{\circ} \mathrm{C}$ are found in sample C. As observed for different polymers exhibiting mesophasic behavior $[2,8,10,15]$, the melting endotherm of the original sample, which appears at $112^{\circ} \mathrm{C}$, is broadly shouldered on the low temperature side. Another interesting observation is the high enthalpy change involved in the liquid crystal-isotropic liquid transition as compared to the melting enthalpy (Table I).

On cooling from the amorphous isotropic liquid, the copolyester $\mathrm{C}$ gives rise to an anisotropic liquid that exhibits a texture with focal conics (Fig. 4). The smectic $C$ phase of the copolyester $C$ is identified by isomorphy with the smectic $\mathrm{C}$ phase of the reference compound $F$ (Fig. 5). Besides the smectic $C$ phase of the copolyester $\mathrm{C}$ is miscible with the left handed twisted smectic $C$ phase $\left(S_{C_{g}}^{*}\right)$ of either the chiral compound $\mathrm{G}$ or the optically active substance $\mathrm{H}$ (Fig. $6 a$ and $b$ ). In the figure 6, the abbreviation TS is used to indicate the domains which exhibit the twisted smectic textures shown in figures $7 a$ and $b$. 


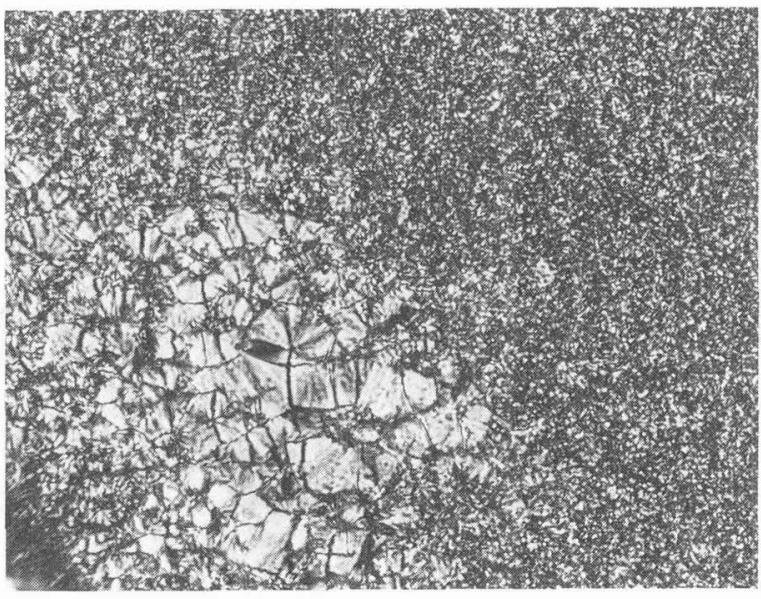

FIG. 4. - Texture of the smectic $\mathrm{C}$ phase of the copolyester C.

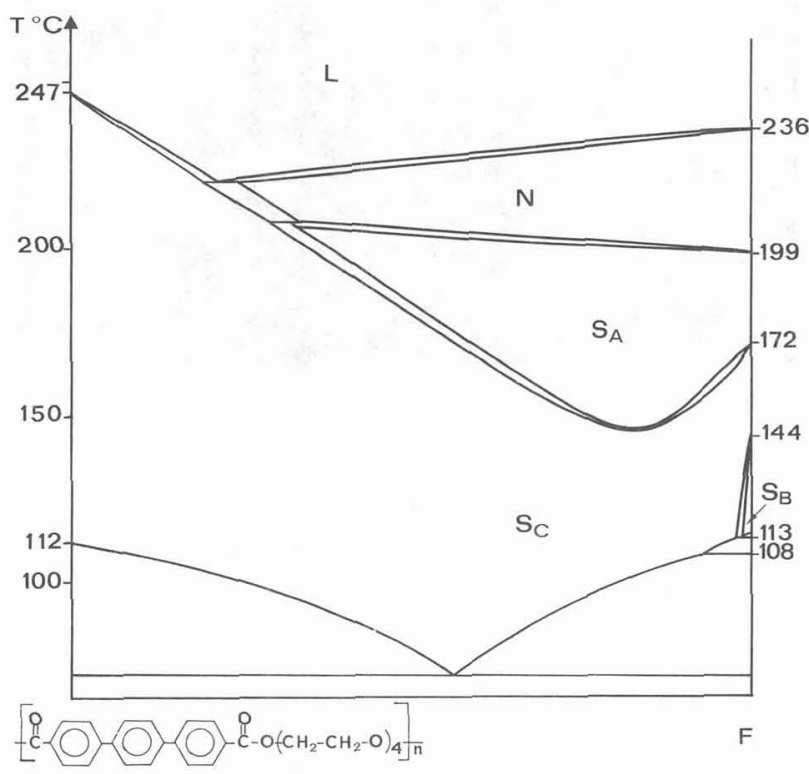

FIG. 5. - Isobaric phase diagram of the mixtures of the copolyester $\mathrm{C}$ and the reference compound $\mathrm{F}$.

4. Conclusion. - In this study, by using the contact method, we have been able to identify the nematic phase of a co[poly(ethylene terephthalate)-p-oxybenzoate] and the smectic $\mathrm{C}$ phase of a copolyester belonging to series of terphenyl derivatives. However, as to the macromolecule organization in the smectic strata, a model is still hypothetical and needs further experimental confirmation.

The conversion of the liquid crystalline polymer phases to the cholesteric or the twisted smectic C form can be performed by the addition of optically active solutes.

Acknowledgments. - The authors acknowledge Pr. G. W. Gray (University of Hull, HUG 7RX,

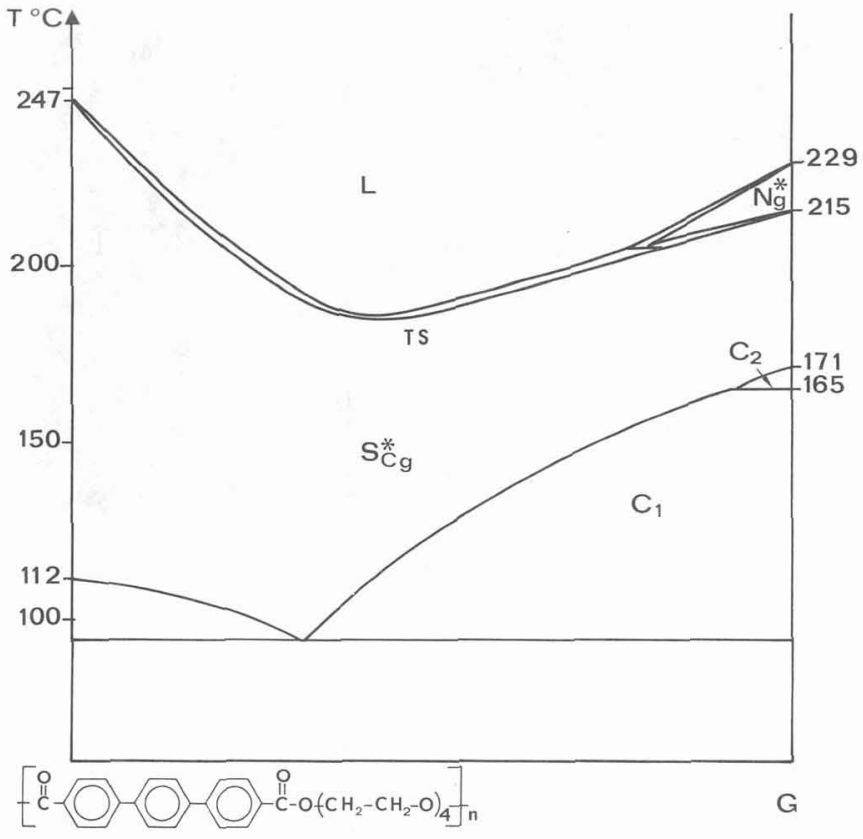

a)

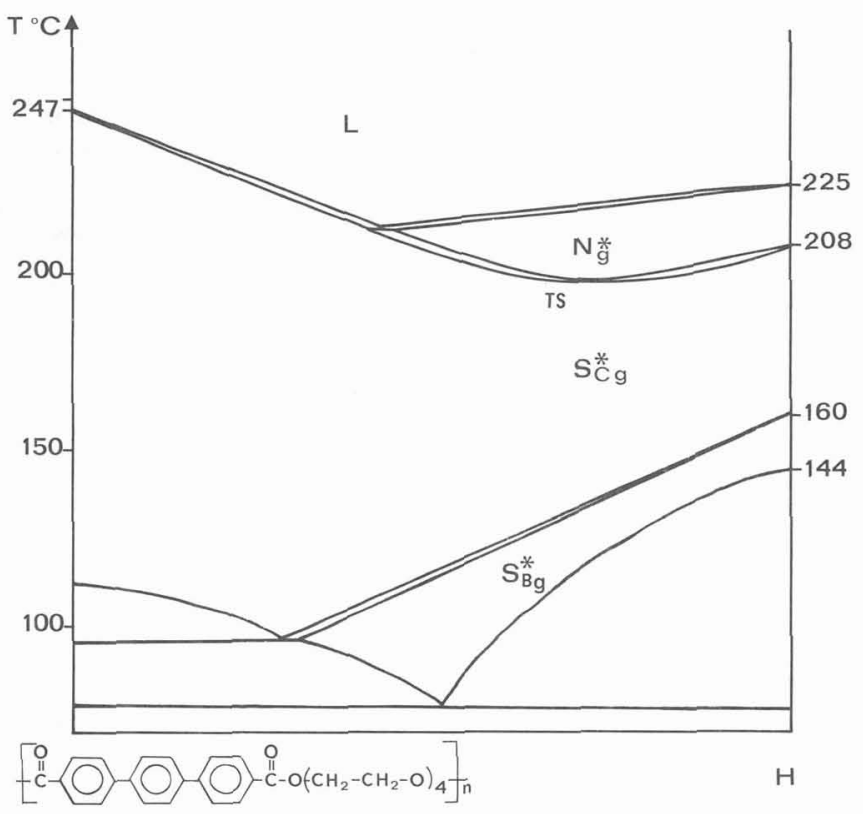

b)

FIG. 6. - Isobaric phase diagram of the mixtures of the copolyester $\mathbf{C}$ and the chiral compound $\mathrm{G}(a) ; \mathbf{H}(b)$.

England), MM. Strzelecki and Liebert (Laboratoire de Physique des Solides, Université de Paris Sud, Centre d'Orsay) and Mrs Leclercq (Laboratoire de Chimie Organique des Hormones, Collège de France, Paris) for the reference compounds $\mathrm{H}, \mathrm{F}$ and $\mathrm{G}$. The authors are also indebted to Professor L. Monnerie (Laboratoire PCSM, 10, rue Vauquelin, 75231 Paris Cedex 05) who suggested this work. 


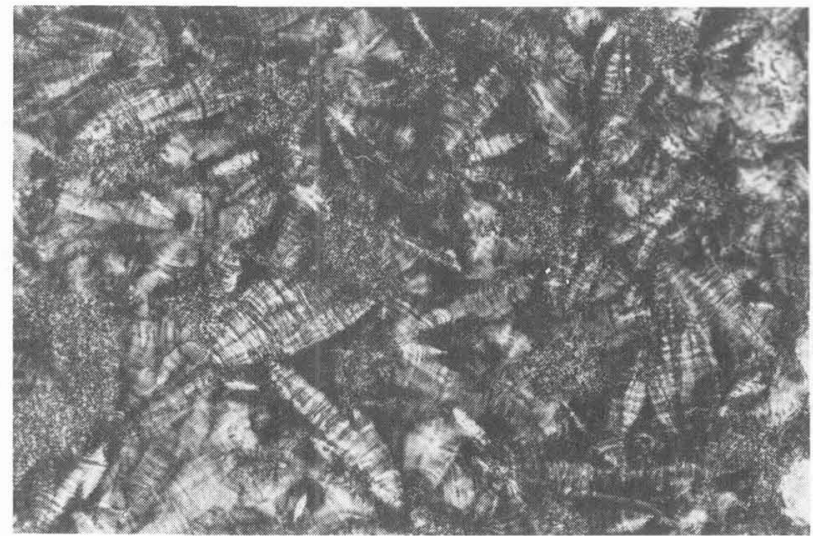

a)

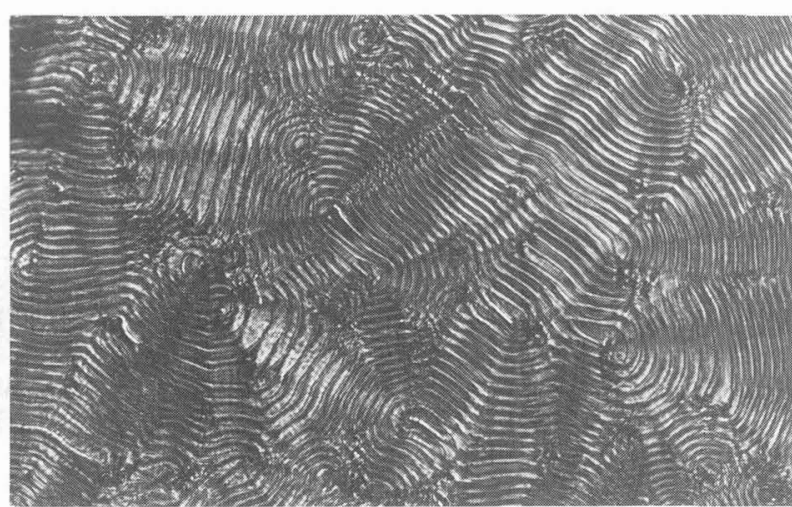

b)

Frg. 7, - Twisted smectic $\mathbf{C}$ textures obtained by the addition of $\mathbf{G}(a)$ or $\mathbf{H}(b)$ to the smectic $\mathrm{C}$ phase of the copolyester $\mathrm{C}$.

\section{References}

[1] Cser, F., Nyitrai, K., Seyfried, E., Hardy, Gy., Europ. Polym. J 13 (1977) 679.

FinkelmanN, H., RingSDORF, H., WendorfF, J. H., Makromol. Chem. 179 (1978) 273.

Blumstein, A., Macromolecules 10 (1977) 872.

Blumstein, A., Blumstein, R. B., Clough, S. B., Hsu, E. C., Macromolecules 8 (1975) 73.

AMerik, Y. B., Krentsel, B. A., J. Polym. Sci. Part. C 16 (1967) 1383.

[2] Roviello, A., Sirigu, A., Polym. Lett. Ed. 13 (1975) 455.

[3] Jackson, W. J., Kuhfuss, H. K., J.P.S., Polym. Chem. Ed. 14 (1976) 2043.

[4] Kuhfuss, H. K., JACKson, W. J. (Eastman Kodak), B.F. 2, 201, 317, U.S. Pat. 3, 778, 410 (1973), U.S. Pat. 3, 804, 805 (1974).

[5] Kleinschuter, J. J., Pletcher, T. C., Shaefgen, J. R. (Du Pont de Nemours), B. Belg. 828935 (1975), B. Belg. 828936 (1975).
[6] Morgan, P. W. (Du Pont de Nemours), B.F. 2, 310, 426 (1976).

[7] McFarlane, F. E., Nicely, V. A., Davis, T. G., Contemporary Topics in Polymer Science 2 (1977) 109.

[8] Krigbaum, W. R., Salaris, F., J.P.S., Polym. Phys. Ed. 16 (1978) 883.

[9] Wang, C. S., Yeh, G. S. Y., Polymer 18 (1977) 1085.

[10] Noel, C., Billard, J., Mol. Cryst. Liq. Cryst. (Letters) 41 (1978) 269

[11] Kofler, L., Kofler, A., Thermomikromethoden (Verlag Chemie, Weinheim) 1954.

[12] Taylor, T. R., Arora, S. L., Fergason, J. L., Phys, Rev. Lett. 25 (1970) 722.

[13] LeclercQ, M., Billard, J., Jacques, J., C. R. Hebd. Séan. Acad. Sci. 266 (1968) 654.

[14] Coates, D., Gray, G. W., Mol. Cryst. Lett. 34 (1976) 1.

[15] Newman, B. A., Frosini, V., Magagnini, P. L., Am. Chem. Soc., Polymer Preprints 18 (1977) 9. 